\title{
USE OF VIDEO ANALYSIS OF CONFLICT SITUATIONS FOR MONITORING THE TRAFFIC ON URBAN ROAD INFLUENCED BY PARALLEL PARKING
}

The paper deals with problems of influence of parallel parking on urban roads for road traffic safety. It shortly refers to evaluation of normative principles related to parking of road vehicles in the Czech Republic.

It presents the results of analysis of traffic participant behavior on the particular section of inhabited area by use of video analysis of conflict situations. Thus it is pointed out to a possibility of application of this methodology in execution of safety inspections on roads, for example.

Keywords: Road Transport, Video Analysis, Conflict Situation, Parking.

\section{Introduction}

Lack of parking places in inhabited areas is thorny topic for majority of towns with developed individual road traffic. The drivers are forced to park in the places where it is prohibited by traffic signs or even by law - even at the risk of increase of dangerousness of this place. However, they often park in full accord with traffic signs, but the parking places marked by this way show their own deficiencies. Then the dangerous conflict situations can arise between parked vehicles (or also their drivers) and vehicles passing through this road. This paper refers to these conflict situations arising in concrete locality with parallel parking.

This paper shows only the selected conflict situations which are most important and which can arise also on other roads with similar cross arrangement.
In the process of observing the conflicts caused by parallel parking the video analysis of conflict situations was used - this method was described in [1]. The principle of this method is in provision of video record of the observed locality and subsequent evaluating the road traffic participant behavior. Conflict situations (i.e. the situations when a dangerousness degree can arise without incidence of traffic accident) are classified according to the situation type, place and way of incidence and above all according to their seriousness. On the basis of the conflict situation video analysis results we can then place proposals for modification of this place with a purpose to increase the traffic safety or traffic flow continuity. Other particular applications of this methodology can be found by the interested person e.g. in [2] or [3].

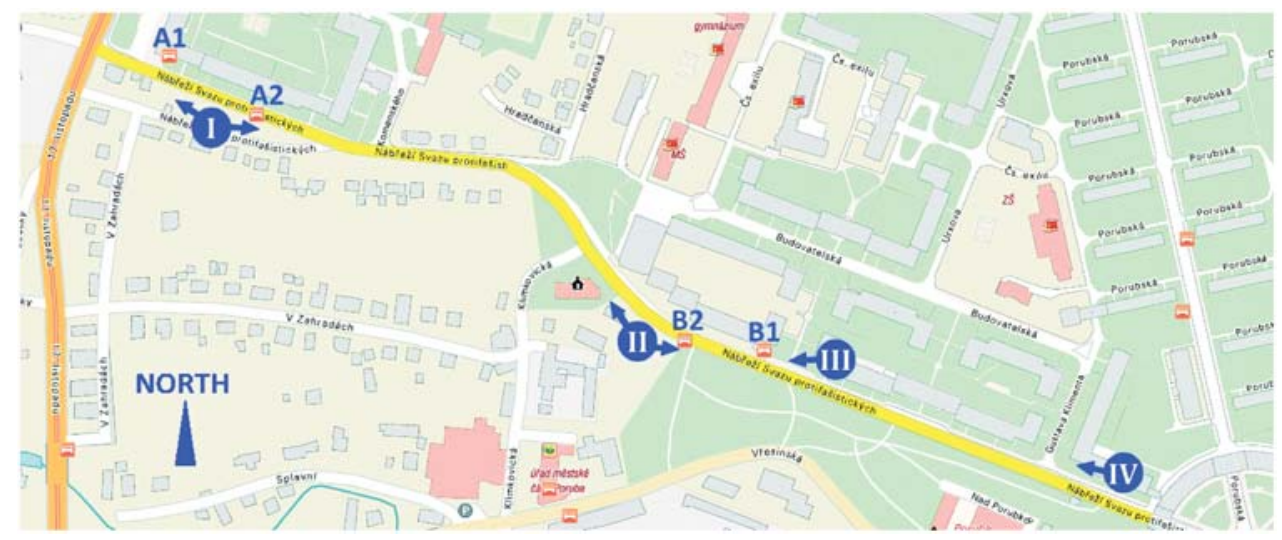

Fig. 1 Monitored locality with marked traffic survey points

\footnotetext{
* Vladislav Krivda, Ivana Mahdalova, Jan Petru

Department of Transport Constructions, Faculty of Civil Engineering, VSB - Technical University of Ostrava, Czech Republic,

E-mail: vladislav.krivda@vsb.cz
} 


\section{Description of the locality monitored}

The detailed analysis of influence of parallel parking on traffic was made on the street "Nabreži Svazu protifasistickych bojovniku" ("Nabrezi SPB" for short) - see Fig. 1. It's a two-lane urban road which contains parallel parking from its greater part. On the road section monitored are also bus stops "Namesti B. Nemcove" (see Fig. 1 - A1 and A2) and "Nabrezi" (see Fig. 1 - B1 and B2). The part between the street "17. listopadu" and "Porubska" was monitored (see Fig. 1 - marked by yellow color).

Four traffic survey points were selected (see Fig. 1 - roman numerals I-IV), from which the video records were made for video analysis of conflict situations. From points I and II the records were made in both direction, as Fig. 1 shows. The views from each individual point are shown on photographs of Figs. 2-4. Parameters of traffic and parking lanes near point IV are shown in Fig. 5.

\section{Sizes of parallel parking places according to ezech norms}

At present the norm CSN 736056 Parking Areas for Road Vehicles since March 2011 [4] is valid in the Czech Republic. Because the vast majority of parking places were built before the launching of this norm, let's see how this problem was solved earlier.
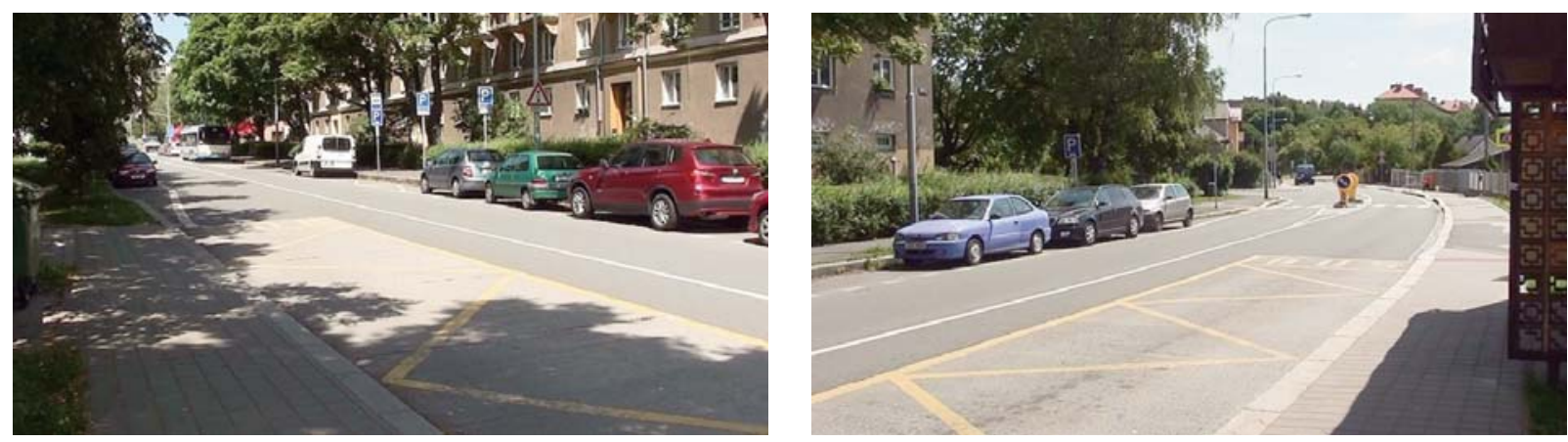

Fig. 2 Views from traffic survey point I
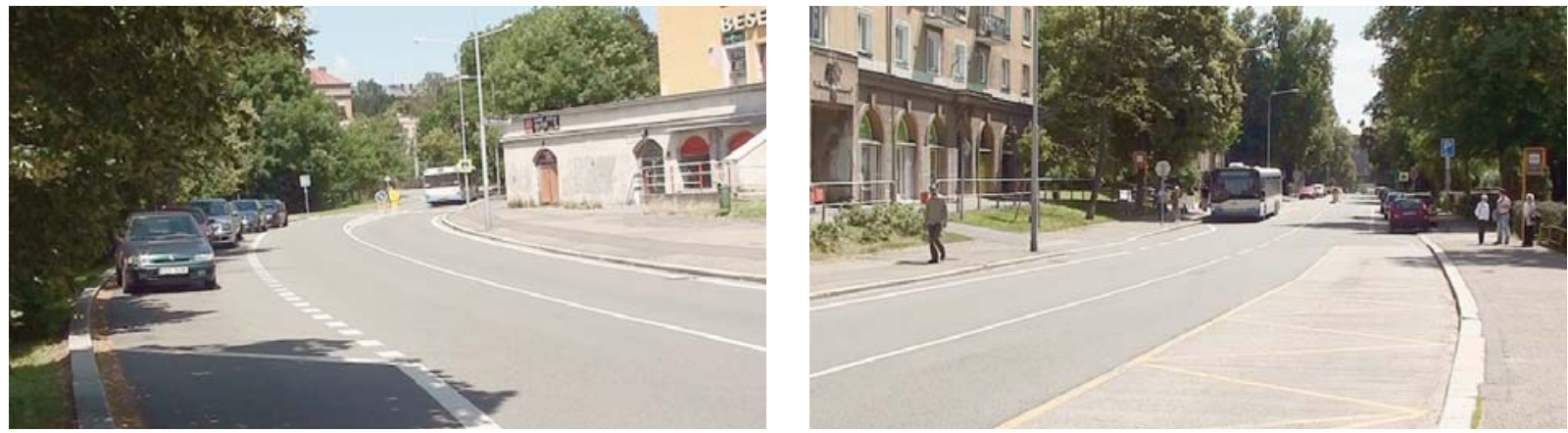

Fig. 3 Views from traffic survey point II
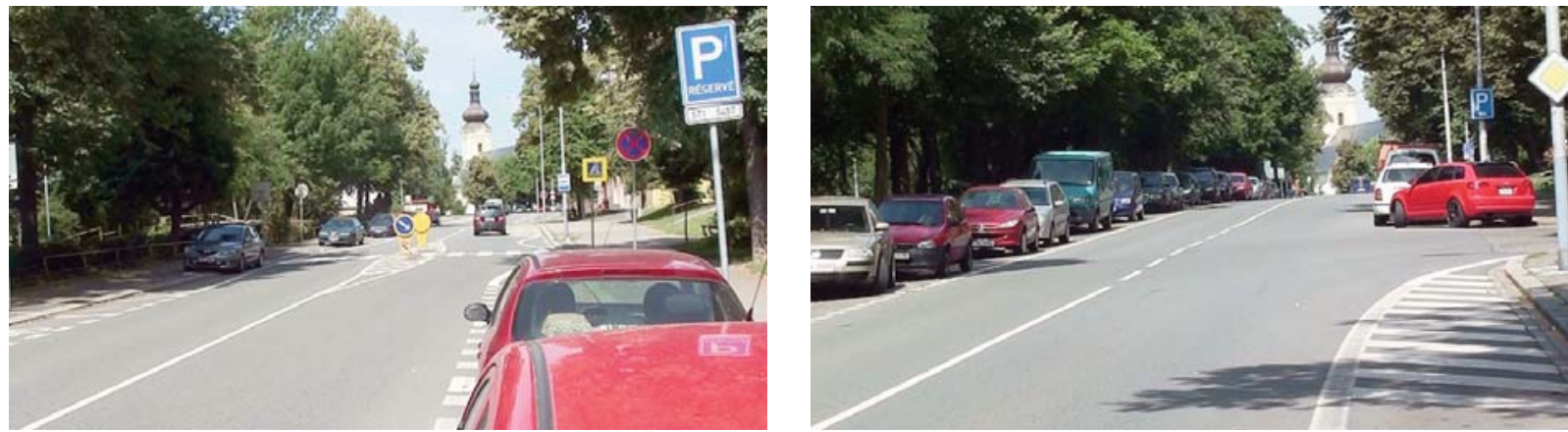

Fig. 4 Views from traffic survey point III (left photograph) and IV (right photograph) 


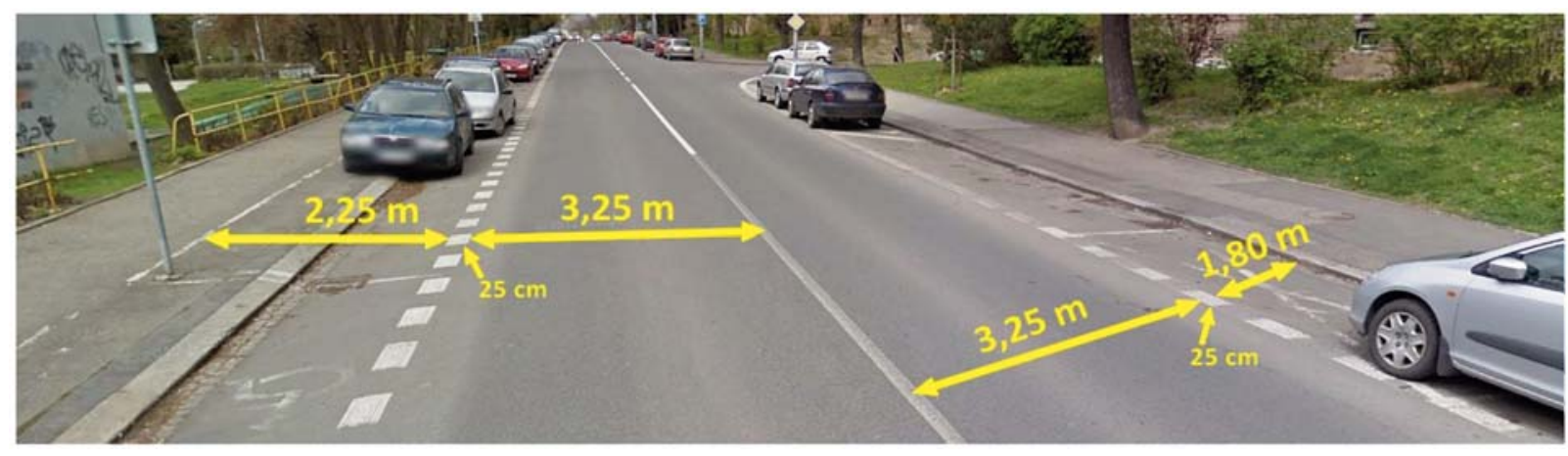

Fig. 5 Width of parking lanes and traffic lanes near point IV

The norm CSN 736056 since 1987 [5] (or its Amendment Z1 since 2001 [6]) was valid before 2011. This norm defined parallel parking places as follows. The width of parking place (see Fig. 6 - size a) for a small or middle passenger car was $2.00 \mathrm{~m}$. The width of parking place for big passenger cars was $2.20 \mathrm{~m}$. The length of the parking place (see Fig. 6 - size b) for a small or middle passenger car was $5.50 \mathrm{~m}$ and for a big passenger car then $6.50 \mathrm{~m}$. These parameters were based on sizes of average vehicles (i.e. small or middle passenger cars with width $1.65 \mathrm{~m}$ and length $4.25 \mathrm{~m}$ and big passenger cars with width $1.80 \mathrm{~m}$ and length $5.00 \mathrm{~m}$ ).

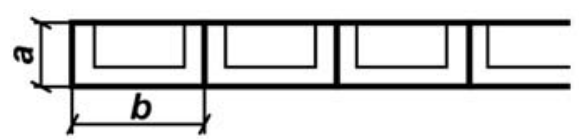

Fig. 6 Width (a) and length (b) of parallel parking place according to CSN 736056 since 1987 [5]

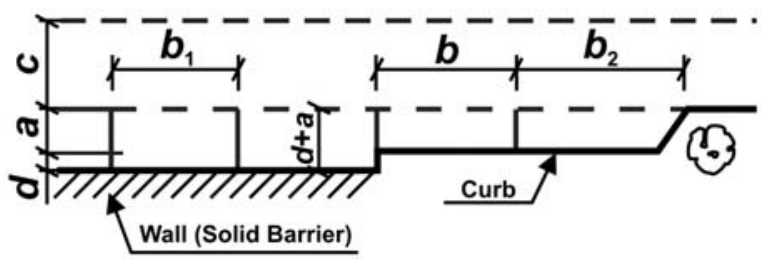

Fig. 7 Sizes of parallel parking places according to CSN 736056 since 2011 [4]

However, the Amendment Z1 in 2001 brought no modifications of parking places. The modifications were made in the norm since 2011 [4] which is a completely new norm for parking areas. This norm already respects bigger sizes of modern vehicles and it also adapts sizes of parking places to them. The sizes of vehicles according to the current norm are as follows - the width of the passenger car (without rear-view mirrors) is $1.75 \mathrm{~m}$ and its length is $4.75 \mathrm{~m}$, the width of the van is then $2.00 \mathrm{~m}$ and length is $6.00 \mathrm{~m}$.

Sizes of parking places are given in Table 1 and are connected with Fig. 7, where $a$ or $b$ is a basic width or length of the parking place, $b 1$ or b2 is length of the parking place with free entry or near planted area, $c$ is a width of adjacent traffic lane, $d$ is distance between the parking place and solid obstacle and sum $\mathrm{d}+\mathrm{a}$ is a real width of the parking place in case of solid obstacle in the level of front door.

Sizes of parallel parking places for passenger cars and

Table 1 vans and width of adjacent traffic lane (see Fig. 7) according to CSN 736056 since 2011 [4]

\begin{tabular}{|c|c|c|c|c|c|c|c|}
\hline Vehicle & Parking way & $\begin{array}{c}\mathrm{a} \\
(\mathrm{m})\end{array}$ & $\begin{array}{c}\mathrm{d} \\
(\mathrm{m})\end{array}$ & $\begin{array}{c}\mathrm{b} \\
(\mathrm{m})\end{array}$ & $\begin{array}{c}\mathrm{b}_{1} \\
(\mathrm{~m})\end{array}$ & $\begin{array}{c}\mathrm{b}_{2} \\
(\mathrm{~m})\end{array}$ & $\begin{array}{c}\mathrm{c} \\
(\mathrm{m})\end{array}$ \\
\hline \multirow{2}{*}{ car } & driving forward & \multirow{2}{*}{2.00} & \multirow{2}{*}{0.40} & 6.75 & 5.25 & 7.75 & 3.25 \\
\cline { 2 - 6 } & reversing & & & 5.75 & - & 6.75 & 3.75 \\
\hline \multirow{2}{*}{ Van } & driving forward & \multirow{2}{*}{2.25} & \multirow{2}{*}{0.40} & 8.25 & 6.50 & 9.00 & 3.50 \\
\cline { 2 - 5 } & reversing & & & 7.50 & - & 8.00 & 3.75 \\
\hline
\end{tabular}

It's evident that modification of the norm was very desirable. Sizes of the vehicles were changed in the last 30 years - which is not only a trend in the Czech Republic, but also in other European states where there are also changes related to normative sizes of parking places (see e.g. [7]).

\section{Video analysis of conflict situations}

This chapter will describe conflict situations discovered by observations which are related to parallel parking of concrete locality. Individual video sequences can be found on the web page https://sites.google.com/site/krivdaspb [8].

The biggest problem during parking maneuvers into the parallel parking place is probably parking with the use of reversing. The driver has to stop in the traffic lane near a free parking place the length of which is considered by him as sufficient for parking of his vehicle. If this vehicle intending to park is followed by other vehicles, they either have to stop and wait for ending the parking 

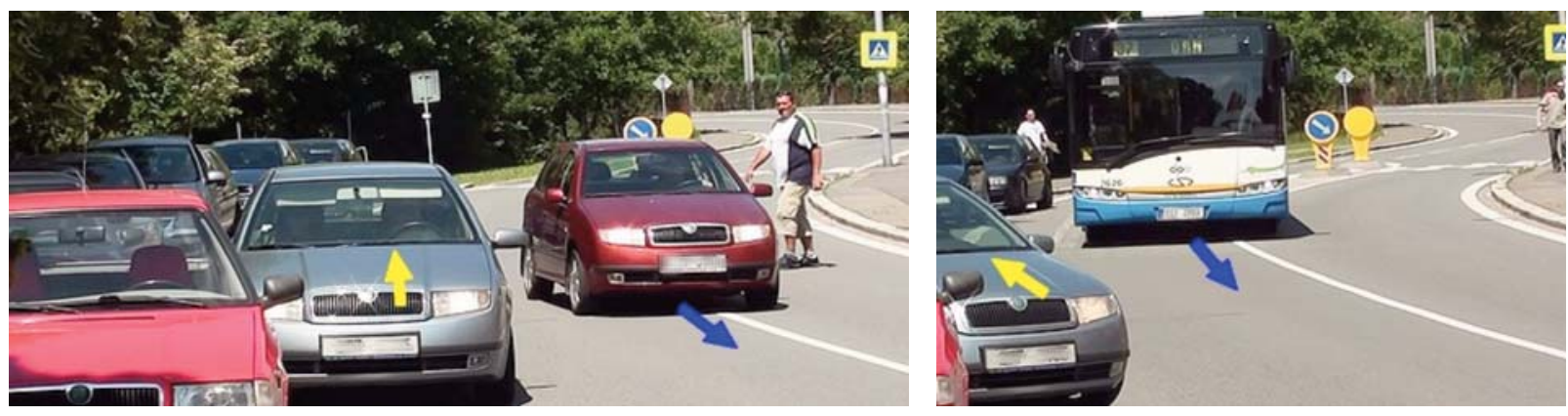

Fig. 8 Driving around vehicle parking by reversing (point II; see VIDEO 01 [8])
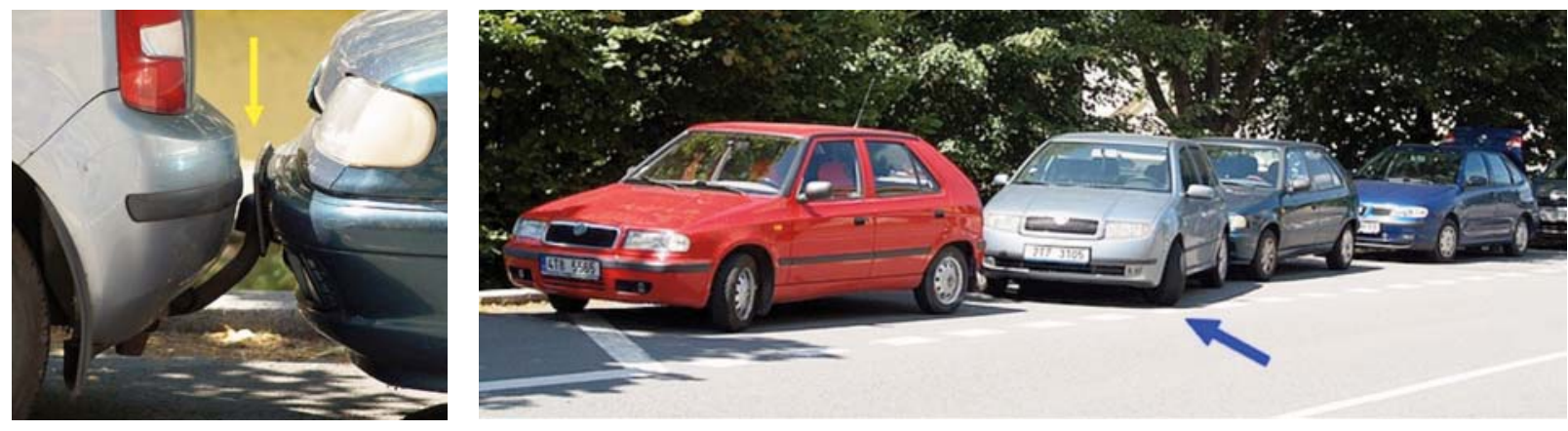

Fig. 9 Unsuccessful parking maneuver (point II)

maneuver (this however results in traffic flow continuity interruption) or drive around this vehicle (usually by driving into opposite direction - see Fig. 8). However, the driving into opposite direction is possible only in case of absence another vehicle which could be restricted or endangered.

If the length of parking place is reckoned by driver wrongly, the other car can be crashed (see Fig. 9 left). And it can also happen that the driver is forced to leave his / her car in an inappropriate position (see Fig. 9 on the right).

The time of parking maneuver by reversing depends then especially on the driver's experiences. In case of a longer time it occurs that a queue of vehicles is formed or other vehicles drive around this vehicle more frequently and they use opposite direction. The similar situation, when the parking maneuver into parallel parking place by reversing took approx 1.5 minute, can be seen in the VIDEO 02 [8].

If the driver decides to drive into parallel parking place by forward driving, he has to have free place of a sufficient length, because this maneuver needs more place (often in case of two or more free parking places in a row). In case of availability of only one free parking place the drivers usually don't use this maneuver. In opposite case the maneuver isn't usually successful and the vehicle isn't parked correctly or after all, the driver goes out from this parking place into the traffic lane and parks his/her car by reversing. Next vehicle can be restricted (or delayed) even in case of successful maneuver, i.e. driving into the parking place by forward driving for the first time - see Fig. 10.

Conflict situations caused by exiting the parking place don't usually arise, because the driver is able to find a needed space in the traffic flow of vehicles, which are going in the traffic lane, using the rear-view mirror.

Another situation is related to the width of traffic lanes and parking lanes (see Fig. 5), because the widths of parking lanes don't comply with present demands - see Chapter 3. The drivers going in the traffic lane drive closer to the middle of road probably

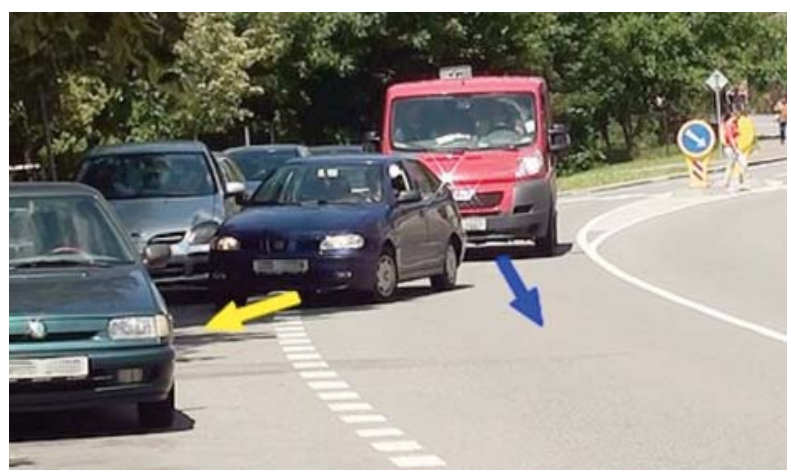

Fig. 10 Delayed vehicle after the vehicle entering the parking place by driving forward (point II; see VIDEO 03 [8]) 

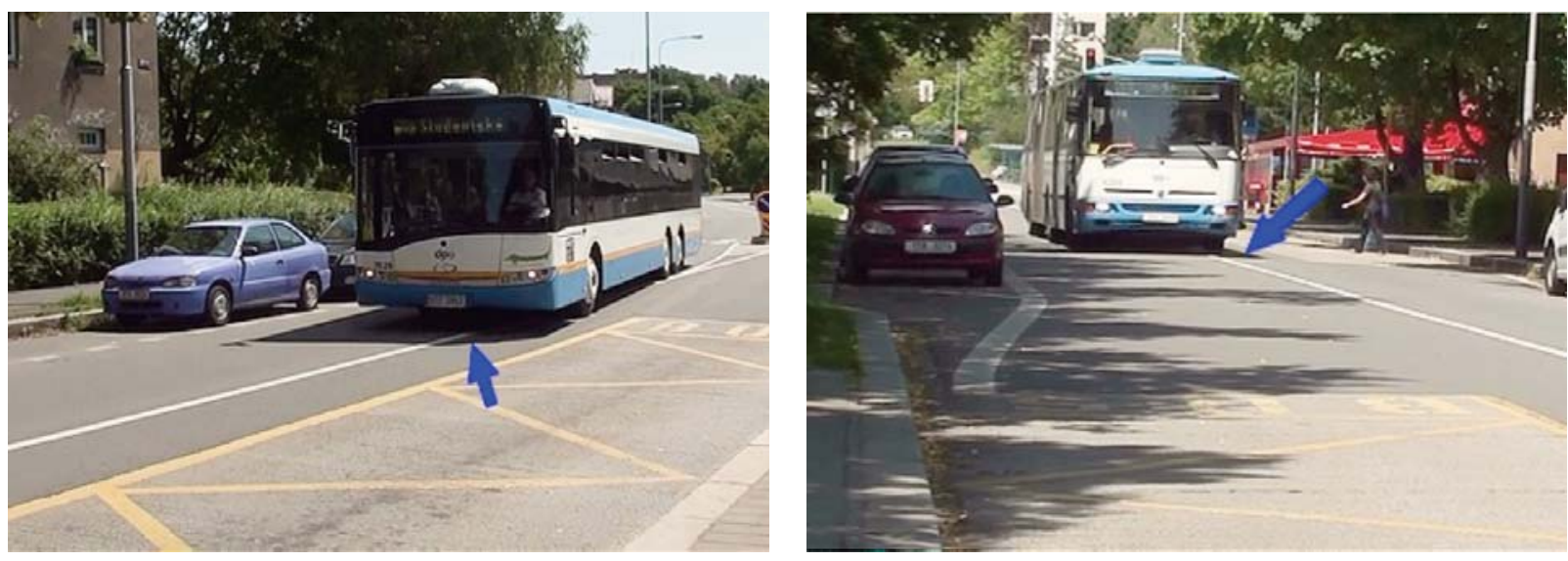

Fig. 11 Crossing the bus into opposite direction due to inadequate width proportions (point I; see VIDEO 04 and VIDEO 05 [8])
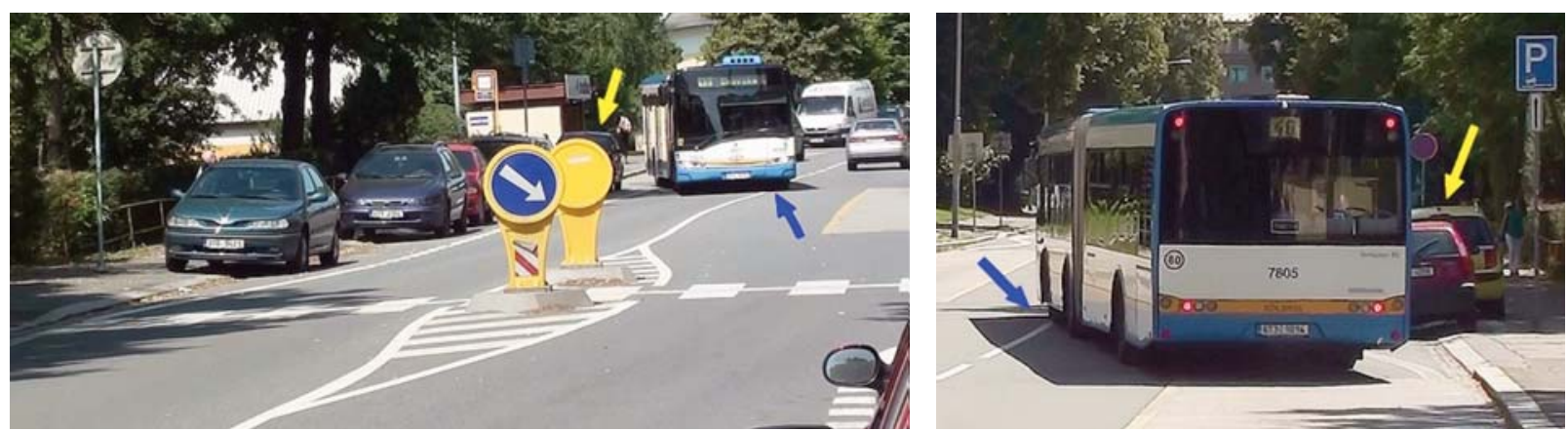

Fig. 12 Exiting the bus from the bus stop influenced by parallel parking places (yellow arrows) and subsequent driving into opposite direction (blue arrows); the left photograph from the point III (see VIDEO 06 [8]) and the right photograph from the point II (see VIDEO 07 [8])

due to keeping safety side distance from the vehicles parked. However it can cause collision with vehicles driving in opposite direction. This distance is respected by drivers of smaller vehicles (i.e. passenger cars), but especially by drivers of larger vehicles (i.e. trucks and buses). The larger vehicles then often have to cross the center dividing line relatively markedly into the opposite direction - see Fig. 11.

Fig. 12 describes another situation when the vehicle (this time it is a bus exiting the bus stop) must drive into opposite direction. It is primarily caused by a relatively small distance between the stop marker and the first parking place. The Photograph in Fig. 12 (or relevant videos) shows the same place from the point of view of different traffic survey points.

Unfortunately, numerous drivers also ignore the fact that parked vehicle can cause restriction of road traffic or even dangerous conflict situation caused again by driving another vehicle into opposite direction - see Fig. 13.

Leaving the parallel parking places has been already mentioned above. If the driver of such a vehicle decides to leave the place in opposite direction compared to the direction in which he/she arrived and in which he/she parked the car, he/she has to carry out a U-turn. In case of absence of other safer alternative (e.g. near roundabout) he/she usually makes it through traffic lanes. This maneuver, which does not have to be successful for the first time, can cause restriction or hazard to other road participants (see Fig. 14 and especially relevant video in which you can see this situation best).

As already mentioned, an array of drivers pass the vehicles parked in a certain safe distance, namely partly to avert damage of their own cars or other vehicles and partly to avert traffic accident in case of the parked vehicle crew's carelessness when they, for example, open the door into the traffic lane. Danger arises especially in such cases when the distance between the vehicle parked and the traffic lane isn't sufficient (it refers to majority of parking places in the observed locality). The crew of the vehicle can be endangered while they are getting out of the car and moving on the road (the driver has no other option, in fact). The same situation, but in reverse order, is shown in Fig. 15, when driver is coming to his/her vehicle (by walking along the traffic line) and opening the door which also sticks out into traffic lane (see also relevant video referred to Fig. 15).

On the road monitored there is another problem, namely inadequate sight proportions for exiting the vehicles from the minor 

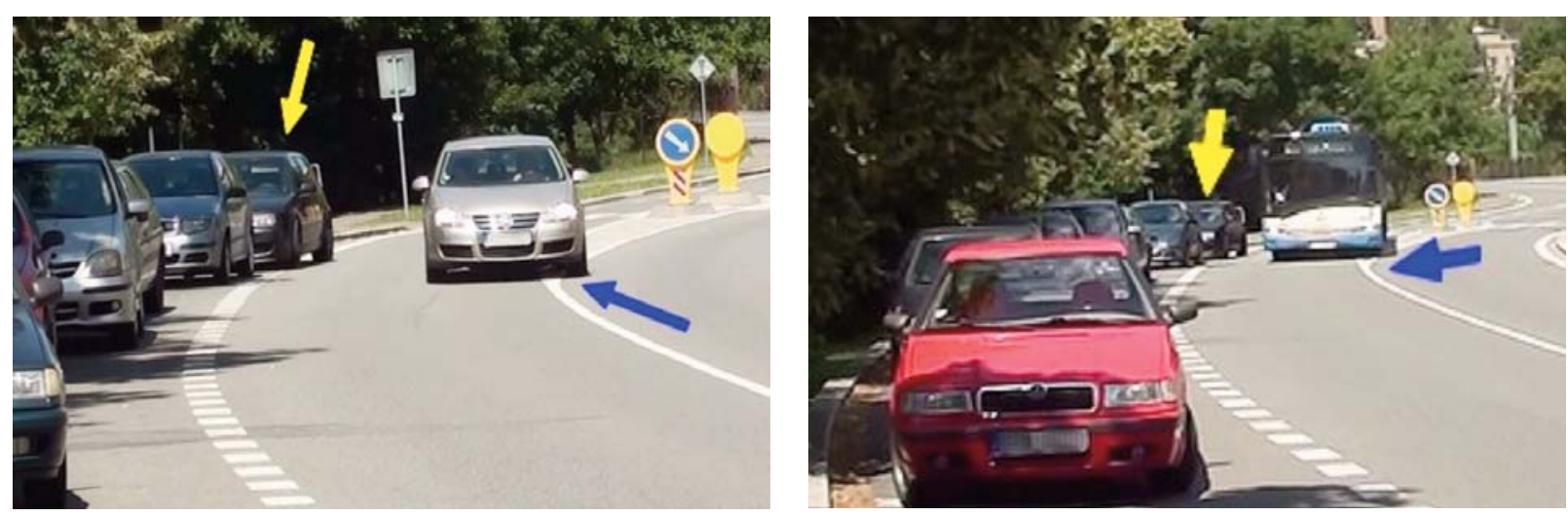

Fig. 13 Driving around a wrongly parked vehicle (yellow arrows) into opposite direction (blue arrows); point II (see VIDEO 08 and VIDEO 09 [8])

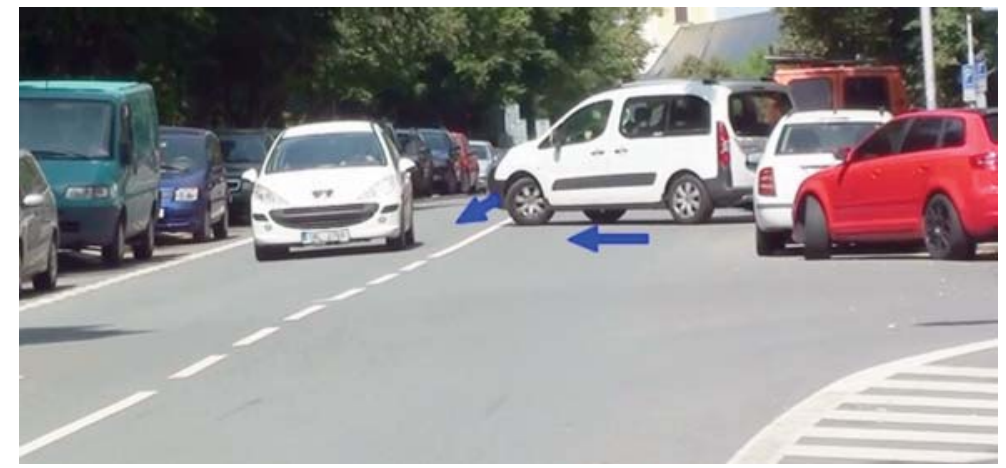

Fig. 14 Turning of the vehicle exiting the parking place (point IV - see VIDEO 10 [8])
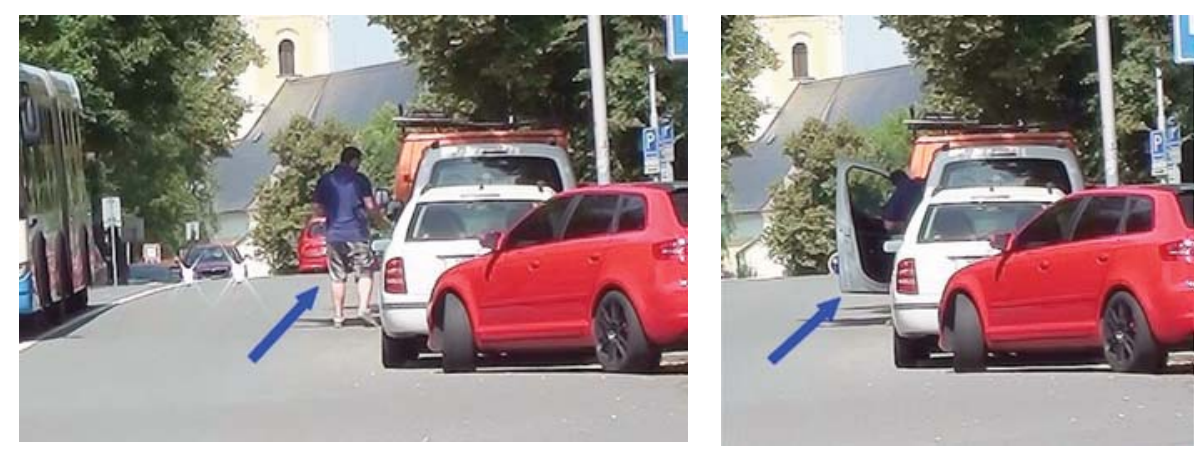

Fig. 15 Open door sticking out into traffic lane and movement of pedestrian (driver) along vehicles parked (point IV - see VIDEO 11 [8])

road into the major road. Such drivers are forced to run into the major road traffic lane relatively noticeably to be able to see an arriving potential vehicle as much as possible - see the left photograph in Fig. 16, where the driver turning left stopped on the major road traffic lane. While turning right the vehicles can in the process of driving around the vehicles parked drive into the opposite direction- see right photograph in Fig. 16, where furthermore the vehicle marked by yellow arrow makes sight proportions worse and the vehicle marked by red arrow can endanger (also by influence of inadequate width of traffic lanes) the vehicle in opposite direction (see blue broken arrow which indicates tugging the steering wheel). Both situations from Fig. 16 are more noticeable from relevant videos. 

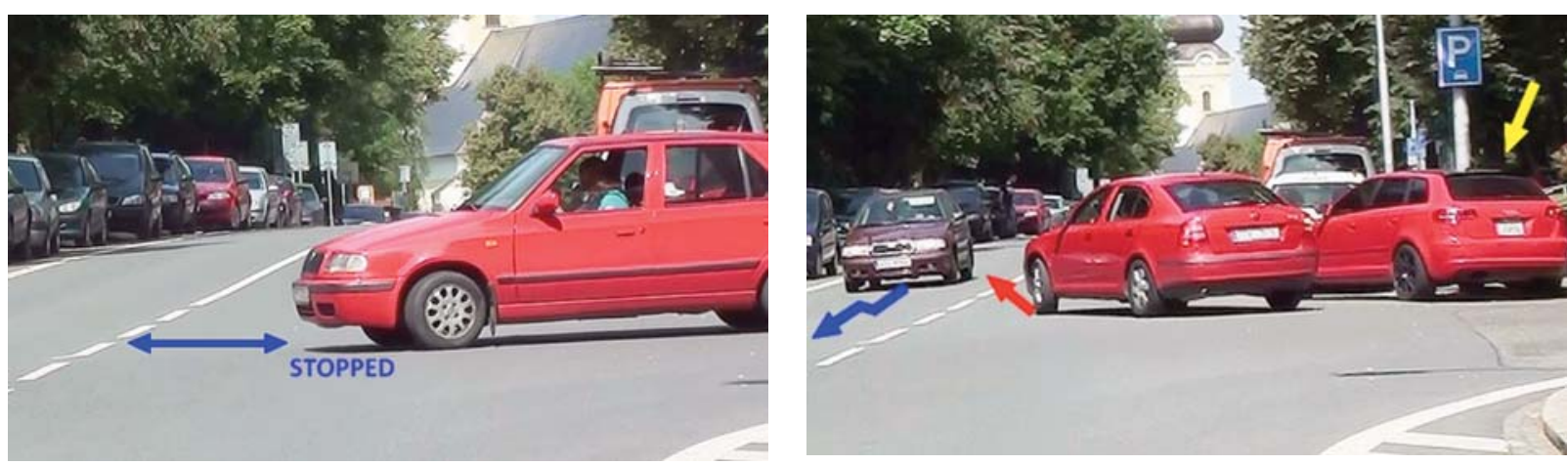

Fig. 16 Conflict situations caused by wrong sight proportions (point IV - see VIDEO 12 and VIDEO 13 [8])

\section{Conclusion}

The above-described conflict situations are only a selection of all situations found out which happened on the road section monitored. It can be however noted that this list of the situations can be used as a general illustration of what can be expected on road with this cross arrangement. The project engineers designing this road didn't certainly mean to make a dangerous section of the road. They rather intended to increase the number of parking places in an inhabited area and maybe to make some traffic calming. Unfortunately, this solution results in above-mentioned problems. On the basis of these pieces of knowledge we can agree with a statement that whichever (even if a positive one) change can cause another problem or several problems (which are often much more serious than before).

The width of the parking place is $2.00 \mathrm{~m}$ according to the valid norm [4] (see Chapter 3 of this paper). If we take the passenger car width into account, which is $1.75 \mathrm{~m}$, then only $25 \mathrm{~cm}$ remain. This space however isn't sufficient for the safe opening of the door, getting the driver out of the car and movement of driver along the vehicle. Besides, unless the driver parks closely to the curb, the distance between the vehicle parked and the traffic lane is decreased. The parking place width of $2.00 \mathrm{~m}$ is thus minimal and in order to ensure the traffic safety on the road with parallel parking it is appropriate to install a so- called maneuver lane between the parking lane and the traffic lane. This lane can serve not only for movement of pedestrians (drivers), but also for simplified parking maneuvers. In case of adequately wide maneuver lane we can expect no conflict situations which were described in Chapter 4 (see for example Fig. 8, 11 and 13).

The paper refers to the fact that the video analysis of conflict situations can be applied very well for detection of problems in road traffic which are relatively serious, but of which there are no (and there cannot be ) any statistic information (compared to the statistics of traffic accidents) in existence. Video analysis of conflict situations is accepted as an instrument for the evaluation of traffic safety at intersections in the Czech Republic. The aim of the project was to prove the suitability of video analysis of conflict situations for the evaluation the safety of static transport. The methodology of the conflicts monitoring with the help of the by video apparatus proves to be a suitable instrument for safety inspections conducting on roads. Initiative for the adjustment the methodology of safety inspection will be prepared in this sense.

A separate question related to influence of parallel parking refers to problems of influencing the capacity of the road considered. That depends on volumes of traffic flows and on numbers of parking maneuvers. In the present Czech norms these problems are not mentioned too elaborately. Nevertheless, the Slovak norms, for example, deal with these problems in more details (see also [9] e.g.). The project results will also be used for the preparation of the initiative to revision of Czech technical standards.

The paper was created with the support of the Ministry of Education, Youth and Sports of the Czech Republic to support of creative activity according to indicator $\mathrm{F}$ which was allocated to VSB-TU Ostrava [10]. In this project and on the basis of the video analysis the authors of this article will be also interested in influence of parking maneuvers on capacity of sections between intersections under Czech traffic conditions, the solution of which is not sufficiently addressed in present norms. The video records were also made from financial resources of the research project of the Ministry of Transport "The Influence of Structural Elements Geometry on the Safety and Fluency of Operation in Roundabouts and Possibility of Rise Crashes Prediction" (Project No. CG911-008-910) [11]. 


\section{References}

[1] KRIVDA, V.: Video-Analysis of Conflict Situations on Selected Roundabouts in the Czech Republic. Communications - Scientific Letters of the University of Zilina, vol. 13, No. 3, p. 77-82, 2011, ISSN 1335-4205. Available in http://www.uniza.sk/komunikacie.

[2] KRIVDA, V., MAHDALOVA, I.: Use of Video Analysis of Conflict Situations by the Evaluation of Inappropriately Designed Building Elements on Roundabouts. Transactions of the VSB - Technical University of Ostrava, Civil Engineering Series. No. 2, 2011, vol. XI, paper \#25 (8 p), DOI 10.2478/v10160-011-0025-8. Publisher Versita, Warsaw, ISSN 1213-1962 (Print) ISSN 1804-4824 (Online).

[3] KRIVDA, V.: Analysis of Conflict Situations on Roundabouts in Valasske Mezirici. Transactions of the VSB - Technical University of Ostrava, Civil Engineering Series. No. 1, 2010, vol. X, paper \#8 (10 p), DOI 10.2478/v10160-010-0008-1. Publisher Versita, Warsaw, ISSN 1213-1962 (Print) ISSN 1804-4824 (Online).

[4] CSN 736056 Parking Areas for Road Vehicles. Praha: Office for Standards, Metrology and Testing, 2011 (in Czech)

[5] CSN 736056 Parking Areas for Road Vehicles. Praha: Office for Standards and Measurement, 1987 (in Czech)

[6] CSN 736056 Parking Areas for Road Vehicles - Amendment Z1. Praha: Czech Standards Institute, 2001 (in Czech)

[7] BRCIC, Davor, Marko SOSTARIC and Marko SEVROVIC. Analytic Determination of Reference Passenger Car Size for Parking Space Dimensioning in Croatia. Promet - Traffic\&Transportation. University of Zagreb, Faculty of Transport and Traffic Sciences, Croatia, vol. 24, No. 3, 2012, pp. 215-222, ISSN 1848-4069 (ISSN 0353-5320 in Web of Science)

[8] KRIVDA, Vladislav, Ivana MAHDALOVA a Jan PETRU. Video Analysis of Conflict Situations on Street "Nabrezi SPB" in OstravaPoruba. 2012. Available in https://sites.google.com/site/krivdaspb (appendix of this paper)

[9] HUSZAROVA, K.: Capacity Calculations of Urban Roads. Thesis. Zilina: University of Zilina, 2011, 87 p., (in Slovak)

[10] KRIVDA, V. et al.: Influence of Parallel Parking on Safety and Capacity of Road Section between Intersections. Project supported from benefit s of Ministry of Education, Youth and Sports of the Czech Republic to support of creative activity according to indicator F which was allocated to VSB-TU Ostrava. Ostrava: VSB-TU Ostrava, Faculty of Civil Engineering. 2012

[11] MAHDALOVA, I. et al.: The Influence of Structural Elements Geometry on the Safety and Fluency of Operation in Roundabouts and Possibility of Rise Crashes Prediction. Project No. CG911-008-910. Project of the Ministry of Transport, Czech Republic. VSB-TU Ostrava, 2009-2010. 